\title{
The (Paleo)Geography of Evolution: Making Sense of Changing Biology and Changing Continents
}

\author{
Joseph G. Meert
}

Published online: 18 April 2012

(C) Springer Science+Business Media, LLC 2012

\begin{abstract}
During the voyage of the H.M.S. Beagle, Charles Darwin quickly realized that geographic isolation led to significant changes in the adaptation of local flora and fauna (Darwin 1859). Genetic isolation is one of the well-known mechanisms by which adaptation (allopatric speciation) can occur (Palumbi, Annu Rev Ecol Syst 25:547-72, 1994; Ricklefs, J Avian Biol 33:207-11, 2002; Burns et al., Evolution 56:1240-52, 2002; Hendry et al., Science 290:516-8, 2009). Evolutionary changes can also occur when landmasses converge or are "bridged." An important and relatively recent (Pliocene Epoch) example known as the "Great American Biotic Interchange" allowed for the migration of previously isolated species into new ecological niches between North and South America (Webb 1985, Ann Mo Bot Gard 93:245-57, 2006; Kirby and MacFadden, Palaeogeogr Palaeoclimatol Palaeoecol 228:193-202, 2005). Geographic isolation (vicariance) or geographic merging (geodispersal) can occur for a variety of reasons (sea level rise, splitting of continents, mountain building). In addition, the growth of a large supercontinent (or breakup) may change the climatic zonation on the globe and form a different type of barrier for species migration. This short review paper focuses on changing paleogeography throughout the Phanerozoic and the close ties between paleogeography and the evolutionary history of life on Earth.
\end{abstract}

Keywords Evolution · Paleogeography · Tectonics

J. G. Meert $(\bowtie)$

Department of Geological Sciences, University of Florida,

241 Williamson Hall,

Gainesville, FL 32611, USA

e-mail: jmeert@ufl.edu

\section{Paleogeomagnetism and Paleogeography}

Reconstructing past maps of the Earth requires the ability to determine both the age of the rocks and the paleoposition of the rocks at the time they formed. Modern geochronological methods such as uranium-lead (U-Pb) and argon-argon ( $\mathrm{Ar}-\mathrm{Ar}$ ) provide precise constraints on the ages of igneous, metamorphic, and sedimentary sequences. When these geochronologic data are tied to the fossil record, it is possible to determine the rates of evolutionary change as well as pinpoint time intervals of radiation and extinction (Bowring and Erwin 1998). Advances have also been made in the study of paleomagnetism that allow us to precisely determine the paleolatitude of ancient landmasses (Van der Voo 1993). The basic assumption in paleomagnetic studies is that the Earth's magnetic field behaves in a dipolar fashion when integrated over a sufficient time interval (Meert 2009). The time required for the average position of the geomagnetic field to approximate the position of the spin axis is thought to be on the order of 7,000-10,000 years. The so-called time-averaged geocentric axial dipole field (or GAD for short) allows us to use the inclination of the magnetic field to position the continents at the proper latitude. In a geocentric axial dipole field, the relationship between inclination and latitude is given by the formula:

$\operatorname{Tan}($ Inclination $)=2 \times \tan ($ Latitude $)$

In a GAD field, the declination recorded by the rock will point either to the north geographic pole (normal field) or to the south geographic pole (reverse field). Any measured declination difference from north or south recorded by the ancient rocks thus indicates the amount of rotation the 
continent has undergone since formation of the rock. These principles are illustrated in Fig. 1a-d. Because the geocentric axial dipolar field is symmetric, the determination of absolute paleolongitude is unconstrained in reconstructions. To help alleviate the problem of longitudinal uncertainty, paleomagnetists rely on additional data to help constrain relative paleolongitudes between the different continents. Relative paleolongitude can be constrained via ocean floor magnetic anomalies, matching geological features (such as mountain chains) or by the distribution of certain fossils (see for example Cocks and Torsvik 2002). Because ocean floor magnetic anomalies can only be reliably traced back to Mesozoic time, reconstructions of Paleozoic and earlier continental reconstructions rely almost exclusively on faunal and geological comparisons (Meert and Lieberman 2004; Cocks and Torsvik 2002).

The mechanisms by which rocks can acquire a memory of an ancient magnetic field are many and varied. A
Fig. 1 a The structure and magnetic inclination lines for a "normal" (e.g. north-seeking) geocentric axial dipole. The spin axis of the Earth is coincident with the magnetic dipole. $\mathbf{b}$ The structure and magnetic inclination lines for a "reverse" (e.g. south-seeking) geocentric axial dipole. The spin axis of the Earth is coincident with the magnetic dipole. c The relationship between magnetic inclination and latitude for both Normal (N) and Reverse (R) magnetic fields. As an example, the magnetic inclination at 60 degrees north in a normal field will be $\sim 74$ degrees. d 1 Hypothetical sampling location on North America. The measured ancient declination in the rock is shown by the arrow and the measured ancient inclination in the rock is given as $I=0$ in this example. 2 Reconstruction of the continent, assuming a normal magnetic field existed during formation of the rock. Notice how the arrow now points to the north and the sampling location is positioned at the equator according to the dipole formula. 3 Reconstruction of the continent, assuming a reverse magnetic field existed during the formation of the rock. Notice how the declination now points due south and the sampling location is positioned at the equator according to the dipole formula
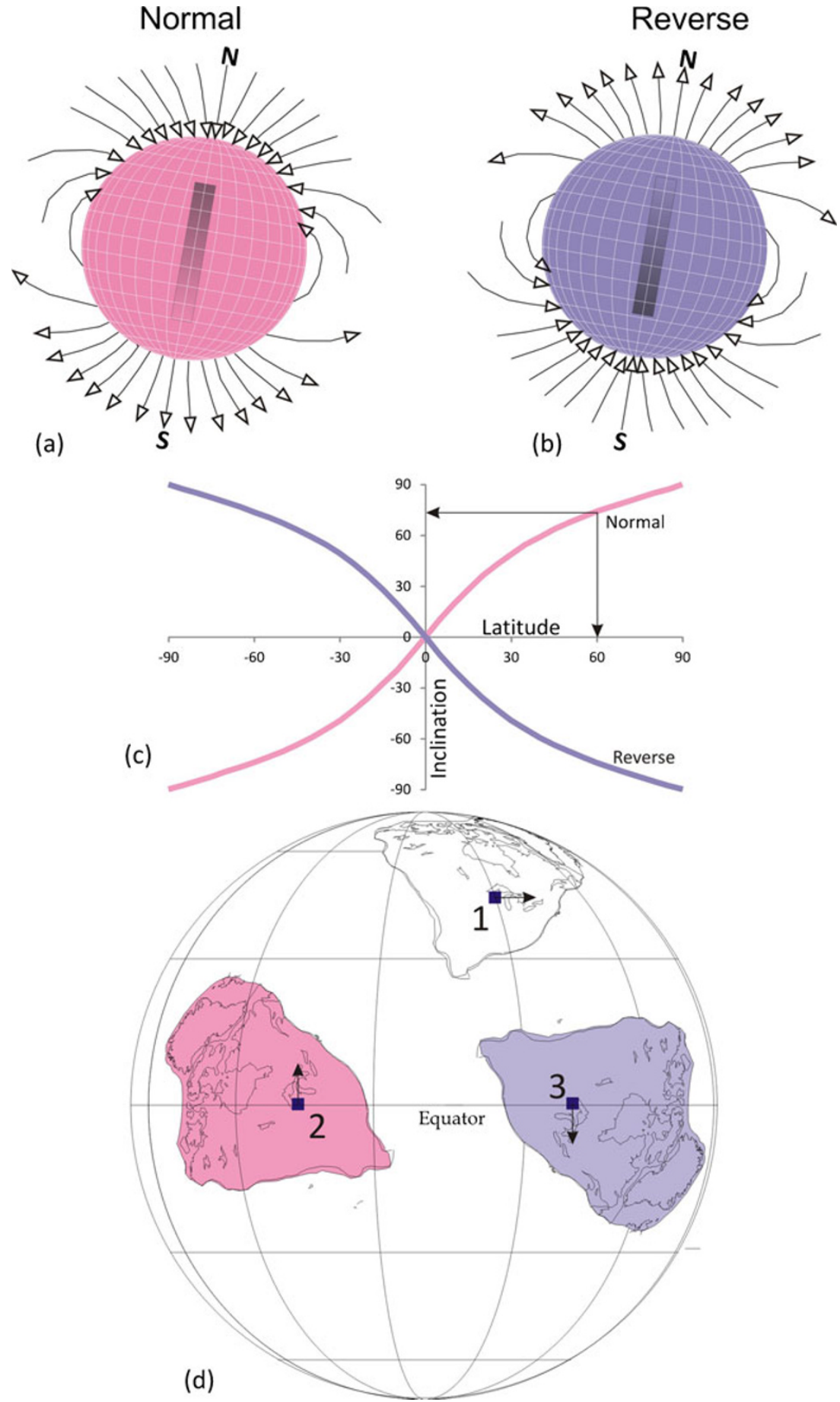

(d) 
comprehensive discussion of remanence acquisition/destruction/alteration in rocks is beyond the scope of this article; however, a detailed description can be found in Butler (1991). For the purposes of this paper, we review two mechanisms by which sedimentary and igneous rocks can acquire a "permanent" memory of the ancient field. Magnetic minerals in igneous rocks (in particular titaniumbearing magnetite) crystallize at elevated temperatures. As the rock cools below a certain temperature $\left(\sim 580^{\circ} \mathrm{C}\right.$ for pure magnetite), the magnetic spin moments in the mineral align themselves with the ambient field (in this case the ancient Earth's magnetic field). This thermoremanent magnetization (or TRM) is illustrated schematically in Fig. 2a. Once this direction is locked into the rock, it will remain locked in for extended periods of geologic time provided the rock is not subjected to significant heating or chemical changes.

Sedimentary rocks may acquire a memory of the ancient field in several ways. One important mechanism of remanence acquisition occurs as a grain of magnetite or hematite (rust) settles to the bottom of the ocean or lake. In the upper parts of

\section{Thermal Remanence Acquisition}

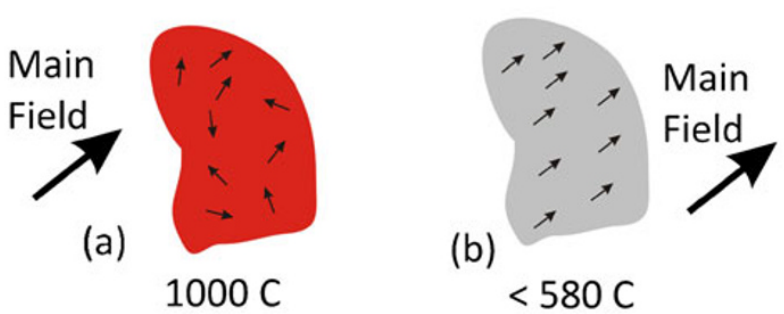

\section{Detrital Remanence Acquisition}

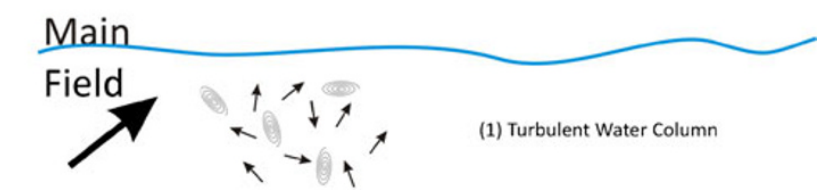

(c)

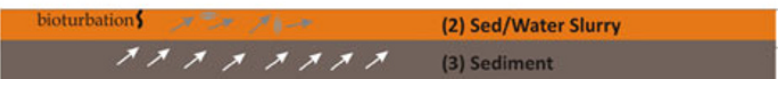

Fig. 2 a Sketch of thermal remanence acquisition in an igneous rock. Magnetite spin axes are randomly distributed in a crystallizing magma at $1,000{ }^{\circ} \mathrm{C}$. b As the rock cools below the Curie temperature of magnetite, the spin moments align with the ambient Earth's field and become locked into the rock. $\mathbf{c}$ Idealized sketch of detrital remanence acquisition. As the magnetic particles fall through the water column, they show no preferential alignment due to small currents and eddies within the water column (point (1)), at point (2), the particles reach the sediment water interface and begin to align with the ambient field though some minor disturbance is possible due to bioturbation or other small currents/eddies within the slurry, and at point (3) the mineral grains become permanently aligned and "locked-in" with the ambient field the water column, the particles are influenced by the Earth's magnetic field, but perturbations in the water column prevent alignment. As the particles reach the quieter interface between the water column and the sediments, they will align themselves with the magnetic field and "lock in" the direction of the field. This is the primary mode of remanence acquisition in sandstones, siltstones and clays, and is called "detrital remanent magnetizaton" and is shown in Fig. 2b. In other sedimentary rocks, magnetic minerals may form via chemical processes and acquire a memory of the field as they grow to a critical size. This method is called "chemical remanent magnetization." As long as the chemical event producing the magnetization in the rocks takes place close to the time of deposition, it can be reliably used to reconstruct the continents.

The magnetic directions locked into the rocks can be studied by collecting oriented samples in the field and then measuring the directions recorded in those rocks back in the laboratory. In practice, paleomagnetists will sample several layers of sedimentary rock or many flows of igneous rocks to assure averaging to the GAD field.

\section{Biogeography and Paleogeography: Some Examples}

In general, reconstructions of the globe back to about 150 million years ago can be reliably obtained by studying the pattern of ocean floor magnetic anomalies along with paleomagnetic data from the continents. Attempts to reconstruct the globe prior to 150 million years ago require integration of various types of data in addition to paleomagnetism in order to reliably produce paleogeographic maps. In the following sections, I show how paleogeography has influenced thinking about evolutionary changes and vice-versa for selected time slices of the Phanerozoic. The paper briefly examines the paleogeography/biogeography at the end of the Cretaceous Period (85 million years ago), the end of the Paleozoic ( $\sim 260$ million years ago) and the Ediacaran-Cambrian transition ( $\sim 570-530$ million years ago) as examples of the interplays between evolutionary history and paleogeography.

\section{Late Cretaceous-85 Million Years Ago}

The Middle Cretaceous (from about 120-100 million years ago) was an interval of major changes in atmospheric chemistry, the pace of sea-floor spreading was high, the magnetic field was in a stable normal polarity "superchron," and average global temperatures were on the rise. By the late Cretaceous, the globe was ice free and a greenhouse climate resulted in elevated sea levels and further isolation of the splitting continents.

A reconstruction of the globe at 85 million years ago is shown in Fig. 3. At 85 million years ago, the dramatic 
changes that occurred during the Middle Cretaceous were waning. The Earth's magnetic field which had been of a single normal polarity for the preceding 40 million years began to reverse. By 85 million years ago, the Atlantic Ocean between South America and Africa was open along with a wide Central Atlantic. The formation of the Atlantic and Indian Oceans separated the once landlocked Gondwana continent that consisted of India, Madagascar, Antarctica, Australia, Africa, and South America (see Fig. 4). According to many paleogeographic models, significant connections between African fauna and the other Gondwana landmasses (Fig. 3) were severely diminished due to the opening of the Southern Atlantic and Indian Oceans along with elevated sea levels (Hedges et al. 1996, 2001; Gheerbrant and Rage 2006).

In contrast, several lines of biogeographic analysis suggest that there were pathways for faunal transfer between the Gondwana continents even into the Paleocene (Vences et al. 2003; Sereno et al. 2004; Van Bocxlaer et al. 2006; Bossuyt et al. 2006). While isolation and rising sea levels played a large role in creating barriers to biological connections, there must have remained some pathways for significant faunal exchanges (Jacobs et al. 2011). In particular, Jacobs et al. (2011) discuss possibilities of "Noah's Ark," "Beached Viking Funeral Ships," and "landspans" across the Gondwana landmasses following the initial work of McKenna (1973). "Noah's Arks" are segments of continental crust that rift away from their larger landmasses and carry with them their biota. The "arks" result in initial isolation of the organisms, but they may also "dock" with a new landmass and introduce their species to a new area.

"Beached Viking Funeral Ships" are similar in that they are also segments of continental crust rifted from one area, but these also may later collide and join new continental regions where the (extinct) biota carried on the funeral ship are now found on a new landmass. Both "Noah's Arks," "Docked Noah's Arks," and "Beached Viking Funeral Ships" are expected occurrences during continental rifting and later collision (Jacobs et al. 2011).

India and Madagascar are argued to be good examples of "Noah's Arks" formed during the rifting of Gondwana. India and Madagascar were isolated from Africa and AustraloAntarctica and ultimately from each other during the Cretaceous and Cenozoic. Jacobs et al. (2011) show that India-Madagascar shared the same "Noah's Ark" dinosaur fauna until their split in the Late Cretaceous. India was also argued to be a good example of a "Beached Viking Funeral Ship" due the fact that its older vertebrate fossils now reside on the Asian continent.

Lastly, Jacobs et al. (2011) also propose a possible series of "landspans" between the Gondwana continents that may have allowed for transfers of biota between the various elements of land before significant separation was achieved by continuing drift; opening of the Indian, Atlantic, and Southern Oceans; and falling sea levels. Due to its long journey northward to Asia, it is possible that India interacted with island arcs or other continents before final docking resulting in a more cosmopolitan Cretaceous fauna (Chatterjee and Scotese 1999; Briggs 2003; Chatterjee et al. 2009).

\section{End Paleozoic/Early Mesozoic_-260 Million Years}

While the Cretaceous was a period of disaggregation of large landmasses, the end of the Paleozoic witnessed the formation of the supercontinent Pangea (Fig. 4). The biogeography of Pangea was influenced by geodispersal,
Fig. 3 Late Cretaceous paleogeography ( $\sim 85$ million years ago). The continents shaded in yellow outline represent the former landmasses of Gondwana and those shaded in orange represent the former landmasses of Laurasia. Laurasia + Gondwana were united in the Pangean supercontinent (see Fig. 4). The red $X^{\prime}$ 's denote presumed physical barriers to faunal migration across Gondwana landmasses. The arrows denote faunal pathways evident in the fossil record

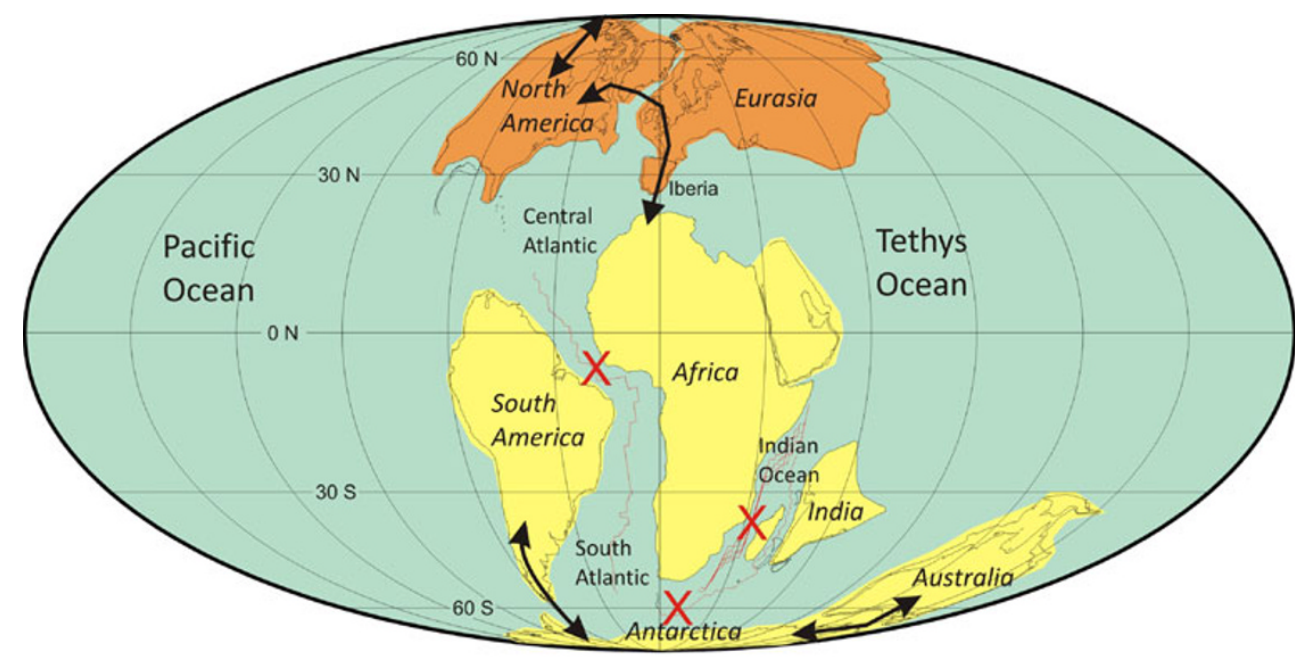

Late Cretaceous ( $85 \mathrm{Ma})$

Gondwana Continents

Laurasian Continents 


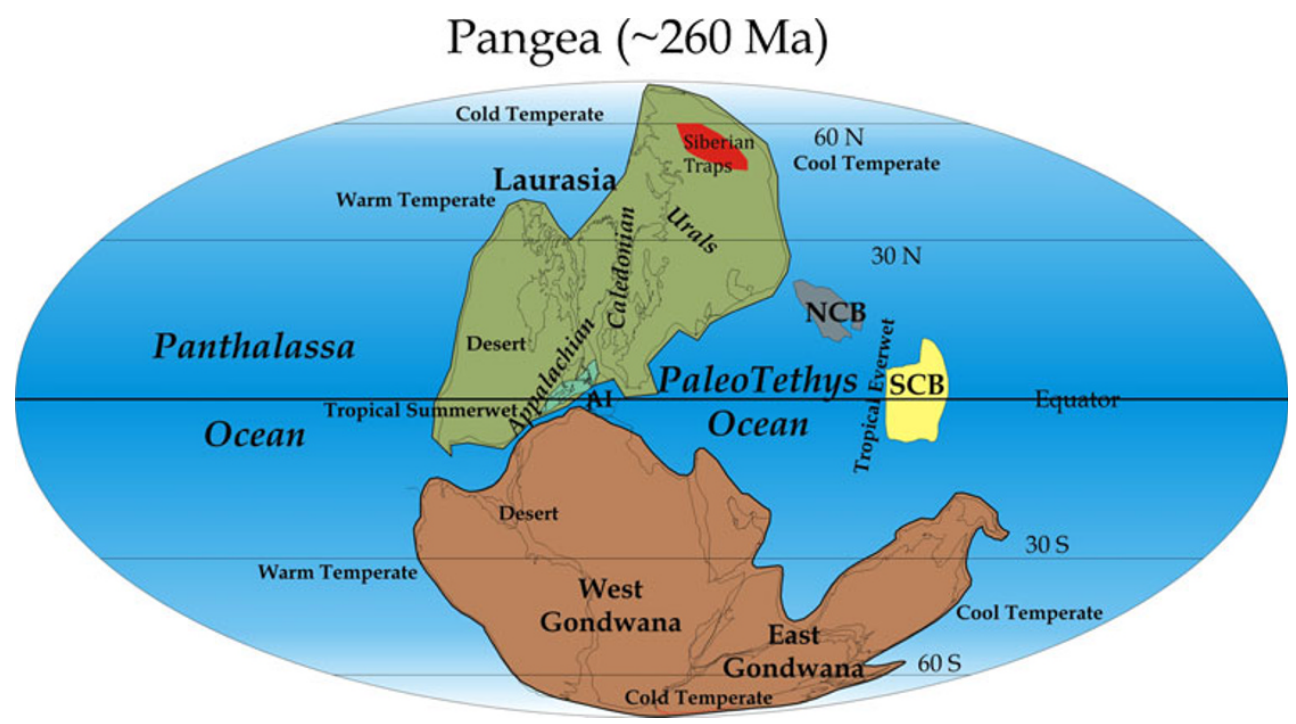

Fig. 4 The supercontinent Pangea during the Late Paleozoic $(\sim 260$ million years ago). The supercontinent was composed of two large halves (Gondwana in the south and Laurasia in the north). The "pacman"-shaped Paleotethyan ocean was located to the east of the supercontinent and separated from the larger Panthalassan ocean by the North China $(N C B)$ and South China $(S C B)$ blocks. Approximate

vicariance, and strong climatic zoning. Species were isolated by the uplift of major mountain chains along the suture zones of Pangea and by the lowering of sea level associated with climatic changes in the Permian, but there were also numerous opportunities for dispersal of biota across the large landmass and surrounding Panthalassic and PaleoTethys Oceans (Ross and Ross 1985; Perez-Huerta 2007).

Pangea also extended through a wide range of climatic zones as the continental landmass stretched from pole to pole (Fig. 4). The poles were cold temperate with winter ice. Interiors of the larger continents (West Gondwana and Laurasia) were deserts and normal latitudinal zoning was present elsewhere (see Fig. 4). This strong climatic zoning may also have influenced provinciality as (for example) certain tetrapod fossils appear to be restricted to specific latitudinal zones in the absence of any physical barriers (Sidor et al. 2004; Whiteside et al. 2011).

It is also interesting to consider the relationship between the large and connected supercontinent and the mass extinction that occurred at the close of the Paleozoic ( 251 million years ago; Benton and Twitchett 2003). Causative mechanisms for the Permian extinction are diverse and range from the effects associated with the massive volcanic outpouring of the Siberian traps, global warming, global cooling, and ocean anoxia (Benton and Twitchett 2003; Becker et al. 2004). Although the exact cause of the extinction is debated, the changes in oceanic circulation brought about by the assembly of Pangea and the fact that the land surface of the Earth was mostly confined to a single hemisphere should not be underestimated. locations of the strong zonal climatic zones are also shown in the figure. The locations of the Appalachian, Caledonian, and Uralian Mountains are shown within Laurasia. AI = Armorica, Avalonia, and Iberia. The location of the slightly younger Siberian traps is also shown for reference

\section{Cambrian-542-525 Million Years Ago}

The interval from 542 to 525 million years ago spans the interval of the so-called "Cambrian Explosion." In a recent article, Meert and Lieberman (2008) summarized the many "triggers" for the massive radiation of life during the Cambrian. The root cause of this expansion of the biosphere remains somewhat of a mystery, although it is clear that a number of external (non-biological) and internal (biological) changes took place on the globe during this time. Figure 5 (from Meert and Lieberman 2008) summarizes many of these changes.

The paleogeographic setting leading up to the Cambrian explosion is controversial. Well-dated paleomagnetic poles sometimes indicate vastly different (or rapidly changing) paleoloatitudes for several continental blocks. In stark contrast to modern-day rates of plate motion (approximately two to eight centimeters per year), the rate of latitudinal motion implied by some of the paleomagnetic data exceed 40 centimeters per year. These rapid changes in plate configuration were interpreted to reflect dramatic (non-tectonic) changes in paleogeography due to true polar wander or inertial interchange true polar wander. In contrast to plate tectonic motions, true polar wander involves the motion of the entire lithosphere (+mantle) as a coherent block. True polar wander occurs due to mass imbalances within the Earth in an effort to maintain a spin axis that is coincident with the maximum inertial moment (Fig. 6). In the special case of inertial interchange true polar wander (or IITPW), the magnitude of the intermediate inertial axis exceeds the magnitude of the maximum intertial axis and causes the 
Fig. 5 (After Meert and Lieberman 2008) Timeline of Gondwana assembly and major "events" in Earth history during the Ediacaran-Cambrian interval. Blue shading shows the approximate number of genera present during the late Ediacaran through Late Cambrian. Major faunal developments are tied to the timeline along with tectonic, climatic, catastrophic events. Abbreviations used: GRB, Gamma ray burst; T. Pedum, Treptichnus pedum trace fossil; $S S F$ 's, small shelly fossils; $B I F^{\prime} s$, banded iron formation, $\mathrm{P}_{2} \mathrm{O}_{5}$, phosphatic horizons; IITP $W$, Intertial Interchange true polar wander; $L I P$, large igneous province

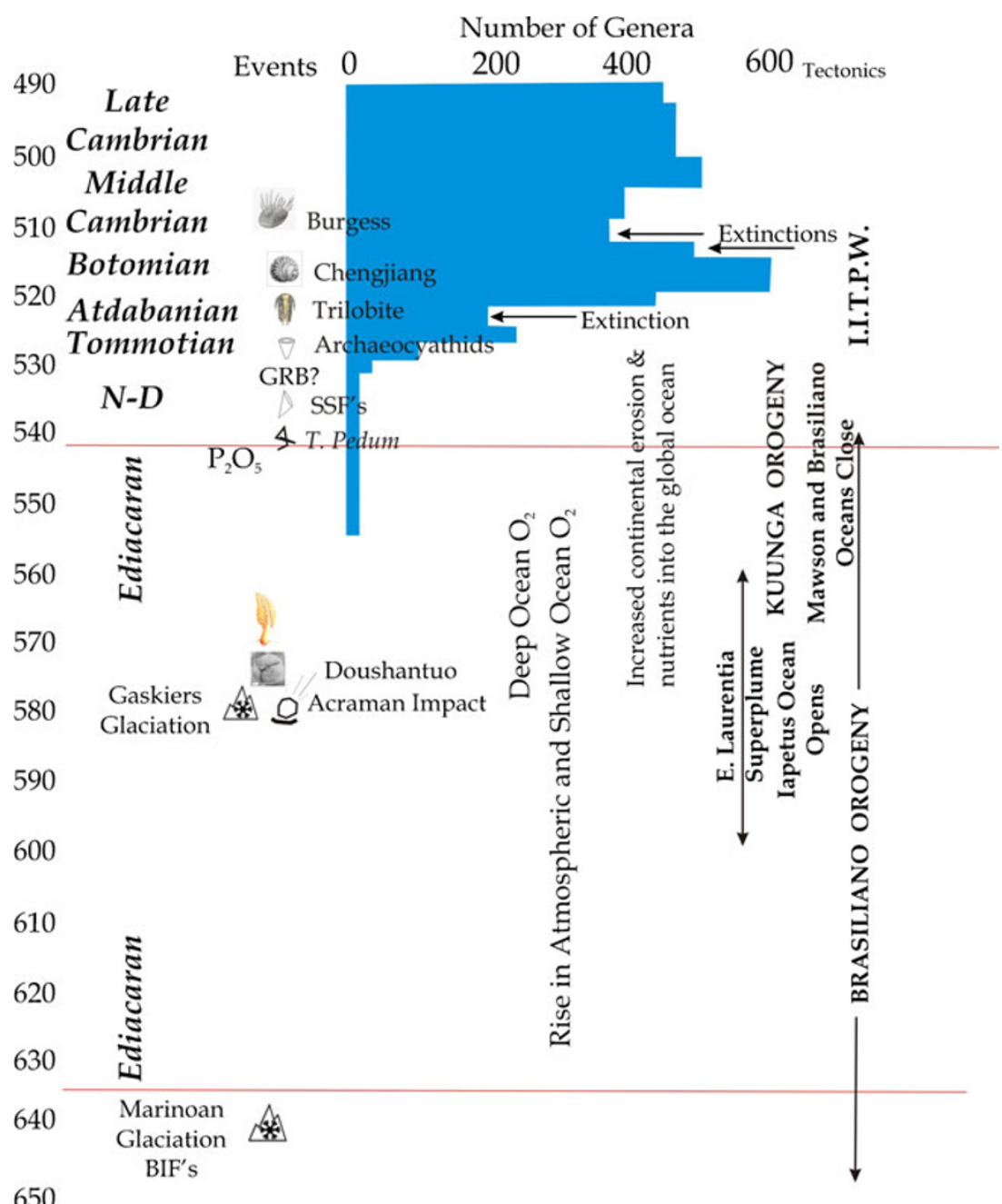

entire lithosphere and mantle to tumble through 90 degrees in as little as 15 million years as the Earth's spin axis realigns to a stable configuration. In the most extreme, but unlikely scenario, it is argued that an IITPW event took place immediately preceding the Cambrian explosion and served as an external trigger for the biological changes in Early Cambrian time (Kirschvink et al. 1997).

From the perspective of the paleomagnetist, it is difficult to sort out all the conflicting models using only magnetic data, and arguments abound regarding their significance

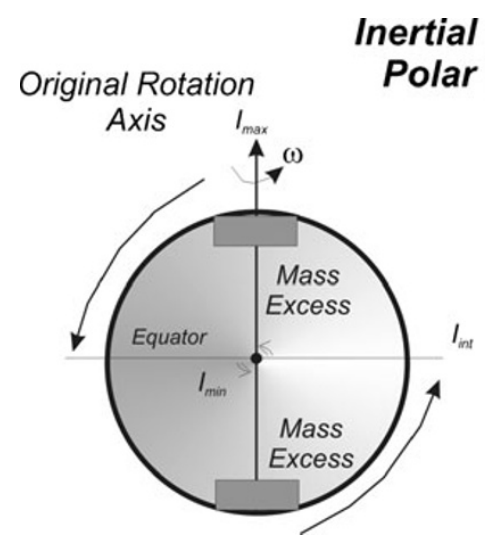

Fig. 6 Cartoon of inertial interchange true polar wander after Meert (1999). In the special case of IITPW, the maximum and intermediate axes of inertia interchange ( $I_{\text {int }}$ becomes $I_{\max }$ and vice versa). The result is that the mantle + lithosphere tumble through 90 degrees. The total time for this reorganization can be as short as 15 million years and could result in drastic changes in paleogeography in a short period of time. $\left(\omega=\right.$ rotation axis, $I_{\min }=$ minimum inertial axis, $I_{\text {int }}=$ intermediate inertial axis, and $I_{\max }=$ maximum inertial axis) 
Fig. 7 (After Meert and Lieberman 2008)

Paleogeographic reconstruction of Tommotian time.

Archaeocyathin realms of Tommotian/Atdabanian time are restricted to the humid tropical zone. Locations of major phosphorite deposits are also shown in the figure

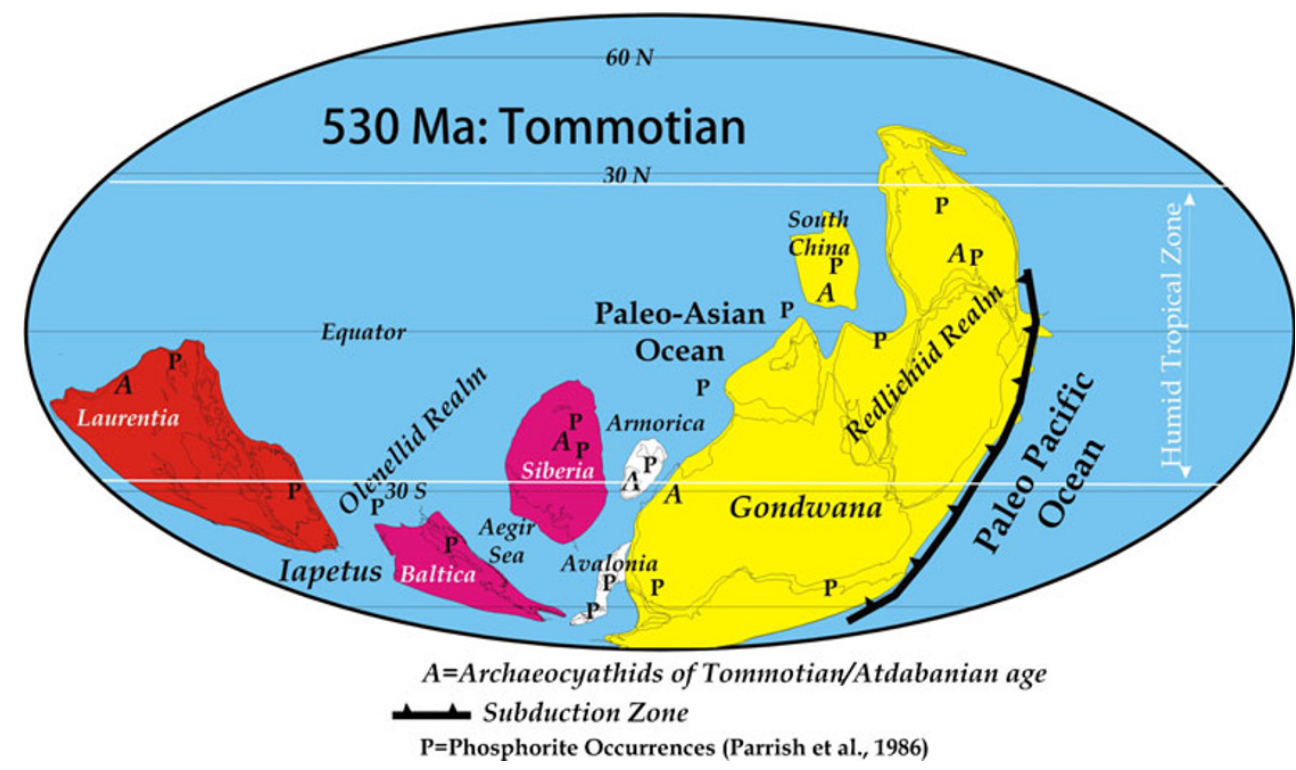

(Kirschvink et al. 1997; Evans 1998; Meert 1999; Meert et al. 2007). In an effort to address this conundrum, Meert and Lieberman (2004) examined the phylogeny of trilobites (with respect to paleogeography) to test the sensitivity of paleogeography to vicariance and geodispersal in early trilobite evolution. Meert and Lieberman (2004) argued that the rapid changes required by the IITPW hypothesis would not produce a robust biogeographic grouping of trilobites such as was documented by Lieberman (1997, 2002). In particular, Meert and Lieberman (2004) showed that the Redlichiina and Olenellid realms were well established by the Early Cambrian ( $\sim 530$ million years ago) indicating that the
Eutrilobita had deeper roots into the Ediacaran period and may have originated in Siberia (Fig. 7; see also Lieberman 2002). Meert and Lieberman (2008) used one particularly contentious paleogeography to show that these realms were established by at least 565 million years ago (Fig. 8). Thus, while the physics of IITPW and TPW indicate that both are probable on Earth, the biogeographic signal of Early Cambrian trilobites argues strongly against rapid transitions in paleogeography such as those required by IITPW for the Early Cambrian (and perhaps Ediacaran). In this example, the evidence from evolutionary biology provides important constraints on our understanding of an otherwise contentious paleogeography.

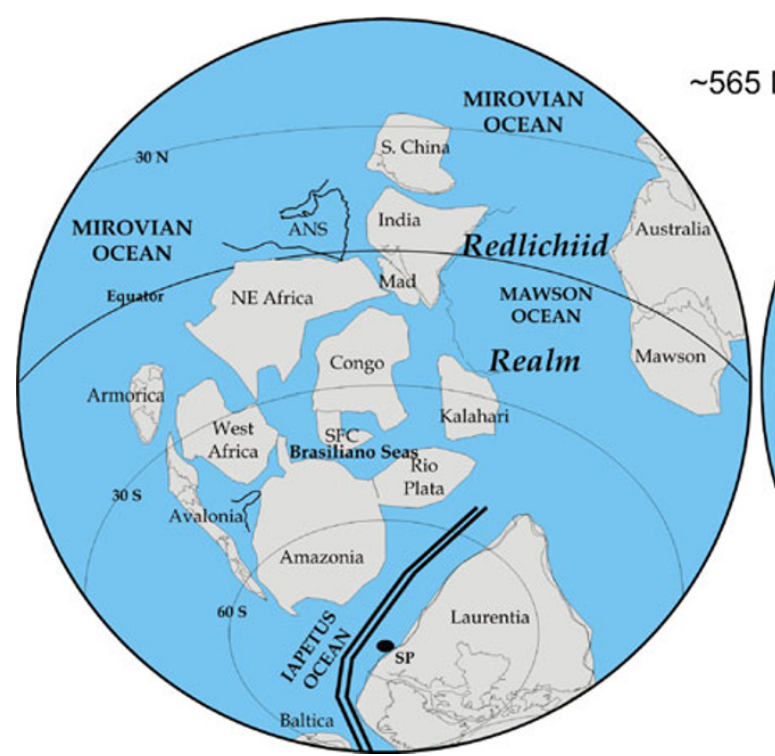

Fig. 8 Paleogeography at 565 million years ago after Meert and Lieberman $(2004,2008)$. The birthplace of the Ediacaran biota was along the borders of the Mirovian and Mawson Oceans. A close relationship between Redlichiid fauna and the margins of the Mawson

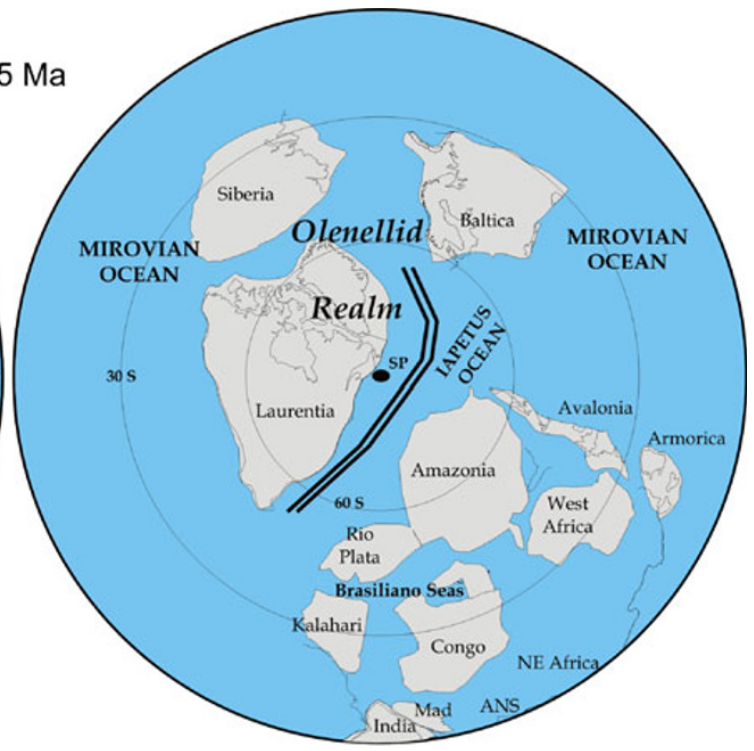

Ocean and the Olenellid fauna with the margins of the Mirovian Ocean suggests that the eutrilobites originated and diversified prior to $\sim 565$ million years ago in accordance with some molecular clock studies of extant organisms 


\section{Conclusions}

Changing paleogeography throughout Earth history played an important role in evolutionary biology. Paleogeographic changes influence evolution in myriad ways including, but not limited to, vicariance, geodispersal, and climatic zonation. Analysis of how flora and fauna are affected by changes in plate tectonic setting and concomitant changes in climate plays an important role in evaluating evolutionary change. This paper briefly reviews three intervals of time and gives examples of how biology and paleogeography are integrated into paleogeographic analyses.

Acknowledgments The author wishes to thank Bruce Lieberman for inviting this contribution and two anonymous reviewers for helpful suggestions that vastly improved the manuscript. Work reported in this paper was supported by grants from the National Science Foundation grants EAR09-10888, EAR04-09101, and EAR05-08597(to JGM).

\section{References}

Becker L, Poreda R, Basu A, Pope K, Harrison T, Nicholson C, et al. Bedout: a possible end-Permian impact crater offshore of northwestern Australia. Science. 2004;304:1469-76.

Benton MJ, Twitchett RJ. How to kill (almost) all life: the end-Permian extinction event. Trends Ecol Evol. 2003;18:358-65.

Bossuyt F, Brown KM, Hillis PM, Cannatella DC, Milinkovitch MC. Phylogeny and biogeography of a cosmopolitan frog radiation: late Cretaceous diversification resulted in continent-scale endemism in the Family Ranidae. Syst Biol. 2006;55:579-94.

Bowring SA, Erwin DH. A new look at evolutionary rates in deep time: uniting paleontology and high-precision geochronology. GSA Today. 1998;8:2-8.

Briggs JC. The biogeographic and tectonic history of India. J Biogeogr. 2003;30:381-8.

Burns KJ, Hackett SJ, Klein NK. Phylogenetic relationships and morphological diversity in Darwin's finches and their relatives. Evolution. 2002;56:1240-52.

Butler RF. Paleomagnetism: magnetic domains to geologic terranes. Cambridge: Cambridge University Press; 1991. 233 pp.

Chatterjee S, Scotese C. The breakup of Gondwana and the evolution and biogeography of the Indian Plate. Proc Indian Natl Sci Acad. 1999;65:397-425.

Chatterjee S, Scotese C. The wandering Indian plate and its changing biogeography during the Late Cretaceous-Early Tertiary period. Platinum Jubilee, Indian Statistical Institute, 2009;60-91.

Cocks LRM, Torsvik TH. Earth geography from 500 to 400 million years ago: a faunal and paleomagnetic review. J Geol Soc London. 2002;159:631-44.

Darwin C. On the origin of species by means of natural selection, or the preservation of favoured races in the struggle for life (1st ed.). London; 1859.

Evans DA. True polar wander, a supercontinental legacy. Earth Planet Sci Lett. 1998;157:1-8.

Gheerbrant E, Rage J-C. Paleobiogeography of Africa: how distinct from Gondwana and Laurasia? Palaeogeogr Palaeoclimatol Palaeoecol. 2006;241:224-46.

Hedges SB. Afrotheria: plate tectonics meets genomics. Proc Nat Acad Sci. 2001;98:1-2.

Hedges SB, Parker PH, Sibley CG, Kumar S. Continental breakup and the ordinal diversification of birds and mammals. Nature. 1996;381:226-29.
Hendry AP, Wenburg JK, Bentzen P, Volk EC, Quin TP. Rapid evolution of reproductive isolation in the wild: evidence from introduced salmon. Science. 2009;290:516-8.

Jacobs L, Strganac C, Scotese C. Plate motions, Gondwana dinosaurs, Noah's arks, beached viking funeral ships, ghost ships, and landspans. An Acad Bras Cienc. 2011;83:3-22.

Kirby MX, MacFadden B. Was southern Central America an archipelago or a peninsula in the middle miocene? A test using landmammal body size. Palaeogeogr Palaeoclimatol Palaeoecol. 2005;228:193-202.

Kirschvink JL, Ripperdan RL, Evans DA. Evidence for large-scale reorganization of Early Cambrian continental landmasses by inertial interchange true polar wander. Science. 1997;277:541-5.

Lieberman BS. Early Cambrian paleogeography and tectonic history: a biogeographic approach. Geology. 1997;25:1039-42.

Lieberman BS. Phylogenetic analysis of some early Cambrian trilobites, the biogeographic origins of Eutrilobita and the timing of the Cambrian explosion. J Paleontol. 2002;692-708.

McKenna MC. Sweepstakes, filters, corridors, Noah's Arks, and beached viking funeral ships in palaeogeography. In: Tarling DH, Runcorn SK, editors. Implications of continental drift to the earth sciences. New York: Academic; 1973. p. 295-308.

Meert JG. A paleomagnetic analysis of Cambrian true polar wander. Earth Planet Sci Lett. 1999;168:131-44.

Meert JG. In GAD we trust. Nature Geoscience. 2009;2:673-4.

Meert JG, Lieberman BS. A palaeomagnetic and palaeogeographic perspective on latest Neoproterozoic and early Cambrian tectonic events. J Geol Soc Lond. 2004;161:477-87.

Meert JG, Lieberman BS. The Neoproterozoic assembly of Gondwana and its relationship to the Ediacaran-Cambrian radiation. Gondwana Res. 2008;14:5-21.

Meert JG, Walderhaug HJ, Torsvik TH, Hendricks BWH. Age and paleomagnetic signature of the Alno carbonatite complex (NE Sweden): additional controversy for the Neoproterozoic paleoposition of Baltica. Precambrian Res. 2007;154:159-74.

Palumbi SR. Genetic divergence, reproductive isolation and marine speciation. Annu Rev Ecol Syst. 1994;25:547-72.

Perez-Huerta A. First record of post-middle Desmoinesian (Late Carboniferous) brachiopods in the Great Basin USA: Implications for faunal migration in response to Late Paleozoic paleogeography. J Paléo. 2007;81:312-30.

Ricklefs RE. Splendid isolation: historical ecology of the South American passerine fauna. J Avian Biol. 2002;33:207-11.

Ross CA, Ross JRP. Carboniferous and early Permian biogeography. Geology. 1985;13:27-30.

Sereno PC, Wilson JA, Conrad JL. New dinosaurs link southern landmasses in the mid-Cretaceous. Proc Roy Soc Lond B. 2004;271:132530.

Sidor CA, O'Keefe FR, Damiani R, Steyer JS, Smith RMH, Larsson HCE, et al. New dinosaurs link southern landmasses in the MidCretaceous. Proc R Soc Lond B. 2004;271:1325-30.

Van Bocxlaer IV, Roelants K, Biju SD, Nagaraju J, Bossuyt F. Late Cretaceous vicariance in Gondwana amphibians. PLoS 1. 2006; e74, doi:10.1371/journal.pone.0000074

Van der Voo R. Paleomagnetism of the Atlantic, Tethys and Iapetus Oceans. Cambridge: Cambridge University Press; 1993. 411 pp.

Vences M, Vieites DR, Glaw F, Brinkmann H, Kosuch J, et al. Multiple overseas dispersal in amphibians. Proc R Soc Lond B. 2003;270:2435-42.

Webb SD. In: Stehli F, Webb S, editors. The great American interchange. New York: Plenum Press; 1985. p. 357-86.

Webb SD. The great American biotic interchange: patterns and processes. Ann Mo Bot Gard. 2006;93:245-57.

Whiteside JH, Grogan DS, Olsen PE, Kent DV. Climatically driven biogeographic provinces of Late Triassic tropical Pangea. PNAS. 2011;108(22):8972-7. 